Louisiana State University

LSU Digital Commons

6-1-2011

\title{
Iron-sulfur proteins are the major source of protein-bound dinitrosyl iron complexes formed in Escherichia coli cells under nitric oxide stress
}

\author{
Aaron P. Landry \\ Louisiana State University \\ Xuewu Duan \\ Louisiana State University \\ Hao Huang \\ Louisiana State University \\ Huangen Ding \\ Louisiana State University
}

Follow this and additional works at: https://digitalcommons.Isu.edu/biosci_pubs

\section{Recommended Citation}

Landry, A., Duan, X., Huang, H., \& Ding, H. (2011). Iron-sulfur proteins are the major source of proteinbound dinitrosyl iron complexes formed in Escherichia coli cells under nitric oxide stress. Free Radical Biology and Medicine, 50 (11), 1582-1590. https://doi.org/10.1016/j.freeradbiomed.2011.03.005

This Article is brought to you for free and open access by the Department of Biological Sciences at LSU Digital Commons. It has been accepted for inclusion in Faculty Publications by an authorized administrator of LSU Digital Commons. For more information, please contact ir@lsu.edu. 


\title{
Iron-sulfur Proteins Are the Major Source of Protein-bound Dinitrosyl Iron Complexes Formed in Escherichia coli Cells under Nitric Oxide Stress
}

\author{
Aaron P. Landry ${ }^{\dagger}$, Xuewu Duan ${ }^{\dagger}$, Hao Huang, and Huangen Ding ${ }^{\star}$ \\ Department of Biological Sciences, Louisiana State University, Baton Rouge, LA, 70803
}

\begin{abstract}
Protein-bound dinitrosyl iron complexes (DNICs) have been observed in prokaryotic and eukaryotic cells under nitric oxide (NO) stress. The identity of proteins that bind DNICs, however, still remains elusive. Here we demonstrate that iron-sulfur proteins are the major source of protein-bound DNICs formed in Escherichia coli cells under NO stress. Expression of recombinant iron-sulfur proteins, but not the proteins without iron-sulfur clusters, almost doubles the amount of protein-bound DNICs formed in E. coli cells after NO exposure. Purification of recombinant proteins from the NO-exposed $E$. coli cells further confirms that iron-sulfur proteins, but not the proteins without iron-sulfur clusters, are modified forming protein-bound DINCs. Deletion of the iron-sulfur cluster assembly proteins IscA and SufA to block the [4Fe-4S] cluster biogenesis in E. coli cells largely eliminates the NO-mediated formation of protein-bound DNICs, suggesting that iron-sulfur clusters are mainly responsible for the NO-mediated formation of protein-bound DNICs in cells. Furthermore, depletion of "chelatable iron pool" in the wild-type $E$. coli cells effectively removes iron-sulfur clusters from proteins and concomitantly diminishes the NO-mediated formation of protein-bound DNICs, indicating that iron-sulfur clusters in proteins constitute at least part of "chelatable iron pool" in cells.
\end{abstract}

\section{Keywords}

nitric oxide; iron-sulfur clusters; chelatable iron pool; dinitrosyl iron complex

\section{Introduction}

NO (nitric oxide) produced from L-arginine by NO synthases [1] or from nitrite by chemical reduction [2] or nitrite reductases [3] has diverse physiological functions. At low concentrations $(\mathrm{nM}), \mathrm{NO}$ acts as a signaling molecule for intercellular communication in neuronal and cardiovascular systems [4]. At high concentrations $(\mu \mathrm{M})$, NO becomes a powerful weapon that kills pathogenic bacteria and cancerous cells [5]. Among cellular targets of NO cytotoxicity are a group of proteins that contain iron-sulfur clusters [6-14]. Iron-sulfur proteins are involved in a broad range of physiological processes from energy

(C) 2011 Elsevier Inc. All rights reserved.

*Correspondence Author: Huangen Ding, Department of Biological Sciences, Louisiana State University, Baton Rouge, LA 70803. Tel: (225) 578 4797; Fax: (225) 578 2597; hding@1su.edu.

These authors contributed equally to this work.

Publisher's Disclaimer: This is a PDF file of an unedited manuscript that has been accepted for publication. As a service to our customers we are providing this early version of the manuscript. The manuscript will undergo copyediting, typesetting, and review of the resulting proof before it is published in its final citable form. Please note that during the production process errors may be discovered which could affect the content, and all legal disclaimers that apply to the journal pertain. 
metabolism to DNA synthesis and repair $[15,16]$. In vitro studies have shown that NO can directly react with iron-sulfur clusters $[17,18]$ forming protein-bound dinitrosyl iron complexes (DNICs) [19-27]. The NO-mediated formation of protein-bound DNICs has also been observed in bacterium Clostridium botulinum where NO is produced from nitrite reduction [28], in activated macrophages where NO is produced by inducible NO synthase $[29,30]$, in tumor cells co-cultured with activated macrophages [31], in the post-operativeday-4 allografts [32], in the gastro-oesophageal junction [11], and in cultured mammalian cells treated with various NO donors [33-36]. When Escherichia coli cells are exposed to pure $\mathrm{NO}$ gas at concentrations $(\mu \mathrm{M})$ that emulate pathophysiological production of $\mathrm{NO}[37$, 38], a large number of iron-sulfur proteins are modified forming protein-bound DNICs [12], suggesting that iron-sulfur proteins are one of primary targets of NO cytotoxicity [8, 10, 12].

NO can also react with small molecule thiols and ferrous iron to form thiol-bound DNICs which have a similar EPR (electron paramagnetic resonance) signal at $g=2.04$ as proteinbound DNICs [39-41]. However, the existence of small molecule thiol-bound DNICs has never been demonstrated in any living cells [42, 43], likely because small molecule thiolbound DNICs are not stable in aqueous solution (e.g. the half-life time of the cysteine-bound DNIC is less than $1 \mathrm{~min}$ ) [27, 44] or are quickly exported by the multidrug resistanceassociated protein-1 [34]. The only stable glutathione-bound DNICs in cells are found to be associated with glutathione $S$-transferases, a potential protection mechanism against excess NO [43]. More recently, it has been postulated that large molecular mass-bound DNICs, instead of small molecule thiol-bound DNICs, are formed in cultured mammalian cells under NO stress [35, 36]. However, the identities of large molecular mass-bound DNICs have not been defined $[35,36]$.

In this study, we combine molecular genetics and biophysics approaches and demonstrate that iron-sulfur proteins are the major source of large molecular mass-bound DNICs formed in E. coli cells under NO stress. Expression of recombinant iron-sulfur proteins almost doubles the amount of protein-bound DNICs formed in E. coli cells under NO stress. Deletion of the iron-sulfur cluster assembly proteins IscA and SufA to block the [4Fe-4S] cluster assembly [45, 46] largely eliminates the NO-mediated formation of protein-bound DNICs in E. coli cells, suggesting that iron-sulfur clusters, but not "free" iron, are mainly responsible for the NO-mediated formation of protein-bound DNICs. Furthermore, depletion of "chelatable iron pool" in the wild-type E. coli cells effectively removes iron-sulfur clusters from proteins and concomitantly diminishes the NO-mediated formation of proteinbound DNICs, suggesting that iron-sulfur clusters in proteins constitute at least part of "chelatable iron pool" in cells. The physiological relevance of the NO-mediated modification of iron-sulfur proteins will be discussed.

\section{Materials and Methods}

\section{Gene cloning and protein purification}

The genes encoding E. coli aconitase B [47], dihydroxyacid dehydratase (IlvD) [48], the redox transcription factor SoxR [22], the heat shock cognate protein HscA [49], and the single-stranded DNA-binding protein SSB [50] were cloned into pET28b+ (Novagen) or pBAD (Invitrogen) expression vectors as described previously [25]. Cloned genes were confirmed by direct sequencing (LSU Gene Lab). Recombinant proteins were expressed in E. coli strain BL21(DE3), MC4100, or the $i s c A^{-1} / s u f A^{-1}$ double mutant [45] cells, and the protein expression was confirmed by the SDS/PAGE analyses. The protein expression clones of $E$. coli ASKA library [51] were also used for the expression of IlvD, SoxR, HscA, and SSB. All protein purification solutions were purged with pure argon gas before use. Recombinant proteins were purified as described in [25], and the purity of purified proteins was over $95 \%$ judging from the SDS/PAGE analyses. 


\section{NO exposure of E. coli cells}

Overnight $E$. coli cells containing protein expression plasmid were diluted 1:100 in freshly prepared LB (Luria-Bertani) medium and incubated at $37^{\circ} \mathrm{C}$ with aeration $(250 \mathrm{rpm})$ for 3 hours, followed by protein induction with IPTG $(100 \mu \mathrm{M})$ or arabinose $(0.02 \%)$ for additional 2-3 hours. For the $i s c A^{-1} / s u f A^{-1}$ double mutant, the cells were grown for 8 hours before protein induction with arabinose for additional 4 hours [45]. Both the wild-type and mutant cells were harvested and re-suspended in the M9 minimal medium to O.D. at $600 \mathrm{~nm}$ of 4.0-6.0. Chloramphenicol $(34 \mu \mathrm{g} / \mathrm{mL})$ was added to the harvested E. coli cells to block new protein synthesis. Cells were then purged with pure argon gas before being treated with the NO-releasing reagent diethylamine NONOate (Cayman Chemical) at $37^{\circ} \mathrm{C}$ for $5 \mathrm{~min}$. Diethylamine NONOate was dissolved in buffer containing Tris (20 mM, pH 10.5), and the concentration of the NONOate was determined from the absorption peak at $250 \mathrm{~nm}$ using an extinction coefficient of $6.5 \mathrm{mM}^{-1} \mathrm{~cm}^{-1}$. Diethylamine NONOate releases 1.5 moles of NO at a half-life time of $2 \mathrm{~min}$ at $37^{\circ} \mathrm{C}(\mathrm{pH}$ 7.4). Released NO was monitored using an NO electrode (World Precision Instruments Inc.). The Silastic tubing NO delivery system [52] was also used for the NO exposure of $E$. coli cells as described previously [12]. Similar results were obtained when $E$. coli cells were exposed to $\mathrm{NO}$ using either diethylamine NONOate or the Silastic tubing NO delivery system.

\section{Depletion of "chelatable iron pool" in E. coli cells}

E. coli cells containing the protein expression plasmid or the vector only were diluted 1:100 in freshly prepared $\mathrm{LB}$ medium and incubated at $37^{\circ} \mathrm{C}$ with aeration $(250 \mathrm{rpm})$ for 3 hours, followed by protein induction with L-arabinose $(0.03 \%)$ for additional 2 hours. Cells were harvested and suspended in the M9 minimal medium to O.D. = 8.0. An iron chelator 2,2'dipydyl was then added to the cells, and incubated at $37^{\circ} \mathrm{C}$ for various time. Cells were then washed once with the M9 minimal medium before being treated with NONOate at $37^{\circ} \mathrm{C}$ for $5 \mathrm{~min}$. For the measurements of "chelatable iron pool" content, the cells were passed through the French press once, followed by centrifugation to remove cell debris. The amount of "chelatable intracellular iron" in cells was measured from the absorption peak at $520 \mathrm{~nm}$ of the iron-dipyridyl complex using an extinction coefficient of $5.2 \mathrm{mM}^{-1} \mathrm{~cm}^{-1}$ [53].

\section{Aconitase activity assay}

For the aconitase activity assay, an aliquot of freshly prepared cell extracts was transferred to a pre-incubated solution containing Tris $(90 \mathrm{mM}, \mathrm{pH} 8.0)$ and $D, L$-isocitrate $(20 \mathrm{mM})$ at $25^{\circ} \mathrm{C}$ as described in [25]. The reaction was monitored at $240 \mathrm{~nm}$ using an extinction coefficient of $3.6 \mathrm{mM}^{-1} \mathrm{~cm}^{-1}$ for aconitate in a Beckman DU640 UV-visible spectrometer equipped with a temperature controller.

\section{EPR measurements}

The X-band EPR spectra were recorded using a Bruker model ESR-300 spectrometer equipped with an Oxford Instruments 910 continuous flow cryostat. Routine EPR conditions were: microwave frequency, $9.47 \mathrm{GHz}$; microwave power, $10.0 \mathrm{~mW}$; modulation frequency, $100 \mathrm{kHz}$; modulation amplitude, $1.2 \mathrm{mT}$; temperature, $25 \mathrm{~K}$; receive gain, $10^{5}$. Freshly prepared glutathione-bound DNIC was used as a reference for quantification of proteinbound DNICs [12]. 


\section{Results}

\section{Recombinant iron-sulfur proteins are modified forming protein-bound DNICs in E. coli cells under NO stress}

When wild-type $E$. coli cells were exposed to NO using the NO releasing reagent diethylamine NONOate, a unique EPR signal at $g=2.04$ reflecting protein-bound DNICs [19-27] appeared, as reported previously [12]. However, when recombinant iron-sulfur protein aconitase B [47] was expressed in the $E$. coli cells, the amount of protein-bound DNICs formed by the same NO exposure was significantly increased (Figure 1A). The titration of the NONOate concentration revealed that the amount of protein-bound DNICs formed in E. coli cells with recombinant aconitase B was about twice as much as that of the $E$. coli cells without recombinant protein when the cells were exposed to $50 \mu \mathrm{M}$ or more of NONOate (Figure 1B).

To further explore the correlation between iron-sulfur proteins and the NO-mediated formation of protein-bound DNICs, we expressed recombinant aconitase B in E. coli cells to various levels, followed by NO exposure. As shown in Figure 2, when the expression level of recombinant aconitase B was gradually increased (panel C), the amount of protein-bound DNICs formed in $E$. coli cells by NO was progressively increased (panel A). In control $E$. coli cells without recombinant proteins (panel C), the total amount of protein-bound DNICs formed by NO remained essentially the same (pane B). Recombinant aconitase B was further purified from the NO-exposed $E$. coli cells. The EPR measurements confirmed that aconitase B was modified forming aconitase B-bound DNIC in $E$. coli after NO exposure (Figure 2D). Double integration analyses of the EPR signal at $g=2.04$ indicated that purified aconitase B-bound DNIC accounted for $45-70 \%$ of the extra protein-bound DNICs formed in the NO-exposed E. coli cells.

To determine whether other iron-sulfur proteins also contribute to the NO-mediated formation of protein-bound DNICs in vivo, we expressed recombinant dihydroxyacid dehydratase which contains a [4Fe-4S] cluster [48] in E. coli cells, and found similar correlation between the expression level of dihydroxyacid dehydratase and the amount of protein-bound DNICs formed in E. coli cells by NO (data not shown). To determine whether non-iron-sulfur proteins can also contribute to the NO-mediated formation of protein-bound DNICs in E. coli cells, we expressed both iron-sulfur proteins and non-iron-sulfur proteins under the same experimental conditions. Figure 3 shows that expression of recombinant iron-sulfur proteins dihydroxyacid dehydratase [48] or the redox transcription factor SoxR [22] increased the amount of protein-bound DNICs in the E. coli cells by at least $100 \%$. In contrast, expression of non-iron-sulfur proteins (the heat shock cognate protein HscA [49] and the single-stranded DNA binding protein SSB [50]) failed to increase the amount of protein-bound DNICs formed in E. coli cells, although both proteins were expressed to similar levels as dihydroxyacid dehydratase and SoxR (Figure 3B). The EPR measurements of recombinant proteins purified from the NO-exposed E. coli cells further confirmed that while iron-sulfur proteins were modified forming protein-bound DNICs, the non-iron-sulfur proteins did not form any DNIC (data not shown). Thus, iron-sulfur proteins, but not the proteins without iron-sulfur clusters, are modified forming protein-bound DNICs in E. coli cells under NO stress.

\section{Deficiency of the iron-sulfur cluster assembly largely eliminates the NO-mediated formation of protein-bound DNICs in E. coli cells}

In E. coli, iron-sulfur clusters are assembled by a group of proteins encoded by two gene clusters iscSUA-hscBA-fdx [54] and sufABCDSE [55]. Among these iron-sulfur cluster assembly proteins, IscA and SufA are paralogs with $47 \%$ sequence identity and $71 \%$ 
similarity. Both IscA and SufA have been proposed as iron donors [46] or alternative scaffold proteins [56] for the iron-sulfur cluster assembly. While deletion of IscA or SufA has only a mild effect in $E$. coli cells, deletion of both IscA and SufA results in deficiency of the $[4 \mathrm{Fe}-4 \mathrm{~S}]$ cluster assembly under aerobic conditions $[45,46,57]$. Both the $i s c A^{-1} / s u f A^{-1}$ double mutant and the wild-type cells were able to express recombinant aconitase $\mathrm{B}$ in the rich $\mathrm{LB}$ medium under aerobic growth conditions (Figure 4A). However, unlike the wildtype cells, the $i s c A^{-1} / s u f A^{-1}$ double mutant failed to assemble the [4Fe-4S] cluster in proteins under aerobic growth conditions [46] (Figure 4B).

The wild-type and the $i s c A^{-1} / s u f A^{-1}$ double mutant $E$. coli cells were then subject to the NO exposure. Figure $4 \mathrm{C}$ shows that NO exposure of the $i s c A^{-1} / s u f A^{-1}$ double mutant cells produced less than $5 \%$ of protein-bound DNICs observed in the wild-type cells. Further increase of NO concentration (up to $500 \mu \mathrm{M}$ NONOate) failed to increase the amount of protein-bound DNICs formed in the $i s c A^{-1} / s u f A^{-1}$ double mutant cells (data not shown). In parallel, the wild-type and the isc $A^{-1} / s u f A^{-1}$ double mutant cells containing recombinant aconitase B were also exposed to NO. Again, unlike in the wild-type E. coli cells, expression of recombinant aconitase $\mathrm{B}$ in the $i s c A^{-1} / s u f A^{-1}$ double mutant cells did not significantly increase the amount of protein-bound DNICs (Figure 4C). Finally, recombinant aconitase B was purified from the NO-exposed wild-type and the $i s c A^{-1} / s u f A^{-1}$ double mutant $E$. coli cells. The EPR measurements confirmed that unlike that in the wild-type cells, recombinant aconitase $\mathrm{B}$ in the NO-exposed $i s c A^{-1} / s u f A^{-1}$ double mutant cells was not modified by NO forming aconitase B-bound DNIC. Similar results were obtained when recombinant dihydroxyacid dehydratase was expressed in the wild-type and the $i s c A^{-1} / s u f A^{-1}$ double mutant $E$. coli cells (data not shown). Thus, deficiency of the iron-sulfur cluster assembly largely eliminates the NO-mediated formation of protein-bound DNICs in E. coli cells.

\section{Depletion of "chelatable iron pool" effectively removes iron-sulfur clusters from aconitase $B$ and diminishes the NO-mediated formation of protein-bound DNICs in the wild-type $E$. coli cells}

"Chelatable iron pool" has been defined as the loosely bound iron that can be depleted by membrane-permeable iron chelators [34]. However, the exact chemical composition of "chelatable iron pool" has not been defined [36, 58]. It would be pertinent to explore the possible link between iron-sulfur clusters in proteins and "chelatable iron pool" in cells.

To test this idea, the wild-type E. coli cells containing recombinant aconitase B were treated with a membrane permeable iron chelator 2,2'-dipyridyl [59], followed by measurements of total aconitase activity in the cell extracts. A protein synthesis inhibitor chloramphenicol was added to block new protein synthesis in the cells before addition of 2,2'-dipyridyl. Because aconitase B requires an intact [4Fe-4S] cluster for its activity [20], removal of ironsulfur cluster from aconitase B would inactivate the enzyme. Figure 5A shows that the total aconitase activity in the E. coli cells was gradually decreased as the concentration of 2,2'dipyridyl in growth medium was increased and nearly abolished after the cells were incubated with $400 \mu \mathrm{M}$ 2,2'-dipyridyl for $40 \mathrm{~min}$.

Recombinant aconitase B was also purified from the $E$. coli cells pre-treated with different concentrations of 2,2'-dipyridyl. Figure 5B shows that the amount of iron-sulfur cluster in recombinant aconitase $B$ (as indicated from the amplitude of the absorption peak at $413 \mathrm{~nm}$ ) was gradually decreased as the concentration of 2,2'-dipyridyl in growth medium was increased. Over $85 \%$ of iron-sulfur clusters in recombinant aconitase B expressed in E. coli cells was removed when $E$. coli cells were treated with $400 \mu \mathrm{M} 2,2^{\prime}$-dipyridyl for 40 min. Similar results were obtained when the $E$. coli cells containing recombinant dihydroxy acid dehydratase [48] were treated with 2,2'-dipyridyl (data not shown). Thus, depletion of "chelatable iron pool" effectively removes iron-sulfur clusters from proteins in E. coli cells. 
The $E$. coli cells pre-treated with various concentrations of 2,2'-dipyridyl were then exposed to $\mathrm{NO}$ as described above. Figure $6 \mathrm{~A}$ and $\mathrm{B}$ show that the amount of protein-bound DNICs formed in the E. coli cells after NO exposure was gradually decreased when concentration of $2,2^{\prime}$-dipyridyl in growth medium was increased, and closely correlated with the amount of iron-sulfur clusters remained in recombinant aconitase B in the cells.

We also followed the time course of the iron-sulfur cluster removal from recombinant aconitase B in E. coli cells in the presence of 2,2'-dipyridyl $(400 \mu \mathrm{M})$. As shown in Figure $6 \mathrm{C}$ and $\mathrm{D}$, the amount of protein-bound DNICs in the E. coli cells was gradually decreased as the cells were incubated with $2,2^{\prime}$-dipyridyl $(400 \mu \mathrm{M})$, and closely correlated with the amount of iron-sulfur clusters remained in recombinant aconitase B in the cells. Taken together of the results shown in Figure 6, we concluded that depletion of "chelatable iron pool" effectively removes iron-sulfur clusters from proteins and concomitantly diminishes the NO-mediated formation of protein-bound DNICs in E. coli cells.

\section{Deficiency of the iron-sulfur cluster assembly reduces "chelatable iron pool" in E. coli cells}

Because depletion of "chelatable iron pool" effectively removes iron-sulfur clusters from proteins, we reasoned that iron-sulfur clusters may be closely associated with "chelatable iron pool" in E. coli cells. To test this hypothesis, we first compared "chelatable iron pool" in the wild-type and the $i s c A^{-1} / s u f A^{-1}$ double mutant $E$. coli cells. Figure 7 shows that "chelatable iron pool" in the $i s c A^{-1} / s u f A^{-1}$ double mutant cells was less than half of that found in the wild-type cells, indicating that deficiency of the iron-sulfur cluster assembly significantly decreases "chelatable iron pool" in E. coli cells. We then compared "chelatable iron pool" in the wild-type and the $i s c A^{-1} / s u f A^{-1}$ double mutant $E$. coli cells containing recombinant aconitase $\mathrm{B}$, and found that expression of recombinant aconitase $\mathrm{B}$ increased "chelatable iron pool" in the wild-type $E$. coli cells but not in the $i s c A^{-1} / s u f A^{-1}$ double mutant cells. Similar results were obtained when dihydroxyacid dehydratase [48] was expressed in the wild-type and the $i s c A^{-1} / s u f A^{-1}$ double mutant cells (data not shown). On the other hand, expression of recombinant non-iron-sulfur proteins HscA [49] and SSB [50] had no effect on "chelatable iron pool" in the wild-type and the $i s c A^{-1} / s u f A^{-1}$ double mutant $E$. coli cells, suggesting that iron-sulfur clusters in proteins constitute at least part of "chelatable iron pool" in E. coli cells.

\section{Discussion}

Recent studies have shown that large molecular mass-bound DNICs are formed in cultured mammalian cells under NO stress $[35,36]$. However, the exact chemical nature of large molecular mass-bound DNICs remains elusive $[35,36]$. In this study, we demonstrate that iron-sulfur proteins are the major source of large molecular mass-bound DNICs formed in $E$. coli cells under NO stress. Expression of recombinant iron-sulfur proteins, but not the proteins without iron-sulfur clusters, almost doubles the amount of protein-bound DNICs formed in E. coli cells under NO stress (Figure 1). Purification of recombinant proteins from the NO-exposed $E$. coli cells further confirms that iron-sulfur proteins, but not the proteins without iron-sulfur clusters, are modified forming protein-bound DNICs (Figures 2 and 3). Deletion of the iron-sulfur cluster assembly proteins IscA and SufA to block the [4Fe-4S] cluster assembly in $E$. coli cells $[45,46]$ largely eliminates the NO-mediated formation of protein-bound DNICs. Furthermore, depletion of "chelatable iron pool" in the wild-type $E$. coli cells effectively removes iron-sulfur clusters from proteins and concomitantly diminishes the NO-mediated formation of protein-bound DNICs, indicating that iron-sulfur clusters in proteins are in dynamic equilibrium with "chelatable iron pool" in cells. 
Previous studies indicated that proteins without iron-sulfur clusters such as bovine serum albumin could also form DNICs with excess ferrous iron and NO in vitro [60, 61]. However, we were unable to observe the DNICs formation in the proteins without iron-sulfur clusters in E. coli cells under NO stress (Figure 3). One possible explanation is that excess iron and NO used in the in vitro studies may form transient DNICs that are subsequently transferred to proteins via thiol-ligand exchange $[60,61]$. It seems that exceedingly low concentration of intracellular "free" iron $[62,63]$ may prevent formation of DNICs in the proteins without iron-sulfur clusters in E. coli cells under NO stress. In contrast, iron-sulfur clusters in proteins are readily modified by NO forming protein-bound DNICs in vitro [19-27] and in vivo [8, 12], and direct modification of iron-sulfur clusters in proteins by $\mathrm{NO}$ has been attributed to the NO-mediated bacteriostasis of $E$. coli under aerobic and anaerobic growth conditions [8, 12] and to the NO-dependent killing of Burkholderia mallei [13]. Thus, at pathological NO concentrations $(\mu \mathrm{M})[37,38]$, iron-sulfur proteins, but not "free" iron, constitute the major source of protein-bound DNICs formed in E. coli cells.

The E. coli mutant with deficiency of the iron-sulfur cluster assembly provides a unique opportunity to further illustrate the role of iron-sulfur clusters in the NO-mediated formation of protein-bound DNICs in vivo. Previous studies showed that deletion of both IscA and SufA results in deficiency of the [4Fe-4S] cluster assembly in E. coli cells under aerobic growth conditions $[45,46]$. Here we find that deficiency of the [4Fe-4S] cluster assembly due to deletion of IscA and SufA largely eliminates the NO-mediated formation of proteinbound DNICs in E. coli cells (Figure 4), demonstrating that iron-sulfur clusters are mainly responsible for the NO-mediated formation of protein-bound DNICs in E. coli cells.

Cellular "chelatable iron pool" has been described as the iron content that can be depleted with membrane-permeable iron chelators [34], and has been proposed as the major iron source for formation of large molecular mass-bound DNS under NO stress [34-36]. However, the exact chemical composition of "chelatable iron pool" has not been defined $[35,36,58]$. It is also possible that bacteria and mammalian cells may have distinct "labile iron pool". In this study, we find that depletion of "chelatable iron pool" with a strong iron chelator 2,2'-dipyridyl effectively removes iron-sulfur clusters from recombinant aconitase B (Figure 5) or dihydroxyacid dehydratase in E. coli cells. We propose that iron-sulfur clusters are at least part of "chelatable iron pool" in bacterial cells. The equilibrium between "chelatable iron pool" and iron-sulfur clusters in proteins was previously implicated in regulation of the iron regulatory protein IRP-1/cytosolic aconitase in mammalian cells [62, 63]. IRP-1 is an iron-sulfur protein with cytosolic aconitase activity. When "chelatable iron pool" is depleted, the [4Fe-4S] cluster in IRP-1 is removed, resulting in apo-IRP-1 that binds the iron responsive elements (IREs) of target mRNAs to promote intracellular iron content $(55,56)$. When intracellular iron content is replenished, the $[4 \mathrm{Fe}-4 \mathrm{~S}]$ cluster is re-assembled in apo-IRP-1 to prevent accumulation of excess intracellular iron. Similar equilibrium between "chelatable iron pool" and iron-sulfur clusters in proteins have been reported for the iron-sulfur cluster assembly regulator IscR [64, 65], the anaerobic growth factor FNR [66], and the NO sensor NsrR [14], among other iron-sulfur proteins in bacteria [10, 67]. Our results presented in this study are entirely consistent with the hypothesis that "chelatable iron pool" is in dynamic equilibrium with iron-sulfur clusters in proteins (Figure 6). Although the molecular details underlying iron exchange between "chelatable iron pool" and iron-sulfur clusters in proteins could only be speculated at present, decrease of "chelatable iron content" in the E. coli mutant cells with deficiency of iron-sulfur cluster assembly and increase of "chelatable iron content" in the wild-type E. coli cells containing recombinant iron-sulfur protein aconitase B (Figure 7) clearly suggest that iron-sulfur clusters in proteins at least contribute to part of "chelatable iron pool" in E. coli cells. 
Throughout evolution, iron-sulfur proteins have become integral parts of diverse physiological processes $[15,16]$. Over 500 unique iron-sulfur proteins have been identified in various organisms [15]. Modification of iron-sulfur proteins by NO is expected to have a broad impact on cellular functions. If cells are to survive, the NO-modified iron-sulfur proteins must be efficiently repaired. Although the biomimetic model studies suggest that DNIC may be directly converted back to iron-sulfur clusters [68], the cellular repair mechanism appears to be more complex. It has been shown that the genes encoding the ironsulfur cluster assembly machinery are highly induced in E. coli cells under NO stress [6-9], suggesting that these proteins could be directly involved in repair of the NO-modified ironsulfur clusters. Recently, we have shown that L-cysteine and oxygen are two key components for decomposition of protein-bound DNICs in vitro and in vivo [27]. However, re-assembly of new iron-sulfur clusters must occur in order to fully restore the function of NO-modified iron-sulfur proteins. Understanding the dynamic exchange between intracellular iron and iron-sulfur clusters in proteins will be crucial to elucidate cellular repair mechanism for the NO-modified iron-sulfur proteins.

\section{Acknowledgments}

This work was supported by the Public Health Service Grant (RO1 CA107494) from the National Institutes of Health (to H.D.). X.D. acknowledged the financial support from a training grant by the Chinese Ministry of Education.

\section{Abbreviations}
AcnB
aconitase B
DNIC
dinitrosyl iron complex
EPR
electron paramagnetic resonance
NONOate
Diethylamine NONOate

\section{References List}

1. Alderton WK, Cooper CE, Knowles RG. Nitric oxide synthases: structure, function and inhibition. Biochem J. 2001; 357:593-615. [PubMed: 11463332]

2. Zweier JL, Li H, Samouilov A, Liu X. Mechanisms of nitrite reduction to nitric oxide in the heart and vessel wall. Nitric Oxide. 2010; 22:83-90. [PubMed: 20044016]

3. Corker H, Poole RK. Nitric oxide formation by Escherichia coli. Dependence on nitrite reductase, the NO-sensing regulator Fnr, and flavohemoglobin Hmp. J Biol Chem. 2003; 278:31584-31592. [PubMed: 12783887]

4. Ignarro LJ. Nitric oxide: a unique endogenous signaling molecule in vascular biology. Biosci Rep. 1999; 19:51-71. [PubMed: 10888468]

5. MacMicking J, Xie QW, Nathan C. Nitric oxide and macrophage function. Annu Rev Immunol. 1997; 15:323-350. [PubMed: 9143691]

6. Mukhopadhyay P, Zheng M, Bedzyk LA, LaRossa RA, Storz G. Prominent roles of the NorR and Fur regulators in the Escherichia coli transcriptional response to reactive nitrogen species. Proc Natl Acad Sci U S A. 2004; 101:745-750. [PubMed: 14718666]

7. Justino MC, Vicente JB, Teixeira M, Saraiva LM. New genes implicated in the protection of anaerobically grown Escherichia coli against nitric oxide. J Biol Chem. 2005; 280:2636-2643. [PubMed: 15546870]

8. Hyduke DR, Jarboe LR, Tran LM, Chou KJ, Liao JC. Integrated network analysis identifies nitric oxide response networks and dihydroxyacid dehydratase as a crucial target in Escherichia coli. Proc Natl Acad Sci U S A. 2007; 104:8484-8489. [PubMed: 17494765] 
9. Pullan ST, Gidley MD, Jones RA, Barrett J, Stevanin TM, Read RC, Green J, Poole RK. Nitric oxide in chemostat-cultured Escherichia coli is sensed by Fnr and other global regulators: unaltered methionine biosynthesis indicates lack of S nitrosation. J Bacteriol. 2007; 189:1845-1855. [PubMed: 17189370]

10. Spiro S. Metalloregulatory proteins and nitric oxide signalling in bacteria. Biochem Soc Trans. 2008; 36:1160-1164. [PubMed: 19021516]

11. Asanuma K, Iijima K, Ara N, Koike T, Yoshitake J, Ohara S, Shimosegawa T, Yoshimura T. Fe-S cluster proteins are intracellular targets for nitric oxide generated luminally at the gastrooesophageal junction. Nitric Oxide. 2007; 16:395-402. [PubMed: 17420147]

12. Ren B, Zhang N, Yang J, Ding H. Nitric oxide-induced bacteriostasis and modification of ironsulphur proteins in Escherichia coli. Mol Microbiol. 2008; 70:953-964. [PubMed: 18811727]

13. Jones-Carson J, Laughlin J, Hamad MA, Stewart AL, Voskuil MI, Vazquez-Torres A. Inactivation of $[\mathrm{Fe}-\mathrm{S}]$ metalloproteins mediates nitric oxide-dependent killing of Burkholderia mallei. PLoS ONE. 2008; 3:e1976. [PubMed: 18398486]

14. Yukl ET, Elbaz MA, Nakano MM, Moenne-Loccoz P. Transcription Factor NsrR from Bacillus subtilis Senses Nitric Oxide with a 4Fe-4S Cluster. Biochemistry. 2008; 47:13084-13092. [PubMed: 19006327]

15. Johnson DC, Dean DR, Smith AD, Johnson MK. Structure, function, and formation of biological iron-sulfur clusters. Annu Rev Biochem. 2005; 74:247-281. [PubMed: 15952888]

16. Lill R. Function and biogenesis of iron-sulphur proteins. Nature. 2009; 460:831-838. [PubMed: 19675643]

17. Harrop TC, Tonzetich ZJ, Reisner E, Lippard SJ. Reactions of synthetic [2Fe-2S] and [4Fe-4S] clusters with nitric oxide and nitrosothiols. J Am Chem Soc. 2008; 130:15602-15610. [PubMed: 18939795]

18. Tonzetich ZJ, Do LH, Lippard SJ. Dinitrosyl iron complexes relevant to Rieske cluster nitrosylation. J Am Chem Soc. 2009; 131:7964-7965. [PubMed: 19459625]

19. Drapier JC. Interplay between NO and [Fe-S] clusters: relevance to biological systems. Methods. 1997; 11:319-329. [PubMed: 9073575]

20. Kennedy MC, Antholine WE, Beinert H. An EPR investigation of the products of the reaction of cytosolic and mitochondrial aconitases with nitric oxide. J Biol Chem. 1997; 272:20340-20347. [PubMed: 9252338]

21. Foster MW, Cowan JA. Chemistry of Nitric Oxide with Protein-Bound Iron Sulfur Centers. Insights on Physiological Reactivity. J Am Chem Soc. 1999; 121:4093-4100.

22. Ding H, Demple B. Direct nitric oxide signal transduction via nitrosylation of iron- sulfur centers in the SoxR transcription activator. Proc Natl Acad Sci U S A. 2000; 97:5146-5150. [PubMed: 10805777]

23. Cruz-Ramos H, Crack J, Wu G, Hughes MN, Scott C, Thomson AJ, Green J, Poole RK. NO sensing by FNR: regulation of the Escherichia coli NO-detoxifying flavohaemoglobin, Hmp. Embo J. 2002; 21:3235-3244. [PubMed: 12093725]

24. Rogers PA, Eide L, Klungland A, Ding H. Reversible inactivation of E. coli endonuclease III by nitric oxide via modification of its [4Fe-4S] cluster. DNA Repair. 2003; 2:809-817. [PubMed: 12826281]

25. Duan X, Yang J, Ren B, Tan G, Ding H. Reactivity of nitric oxide with the [4Fe-4S] cluster of dihydroxyacid dehydratase from Escherichia coli. Biochem J. 2009; 417:783-789. [PubMed: 18945212]

26. Ren B, Duan X, Ding H. Redox control of the DNA damage-inducible protein DinG helicase activity via its iron-sulfur cluster. J Biol Chem. 2009; 284:4829-4835. [PubMed: 19074432]

27. Yang J, Duan X, Landry AP, Ding H. Oxygen is Required for the L-Cysteine-Mediated Decomposition of the Protein-Bound Dinitrosyl Iron Complexes. Free Radic Biol Med. 2010; 49:268-274. [PubMed: 20406681]

28. Reddy D, Lancaster JR Jr, Cornforth DP. Nitrite inhibition of Clostridium botulinum: electron spin resonance detection of iron-nitric oxide complexes. Science. 1983; 221:769-770. [PubMed: 6308761] 
29. Lancaster JR Jr, Hibbs JB Jr. EPR demonstration of iron-nitrosyl complex formation by cytotoxic activated macrophages. Proc Natl Acad Sci U S A. 1990; 87:1223-1227. [PubMed: 2153975]

30. Henry Y, Ducrocq C, Drapier JC, Servent D, Pellat C, Guissani A. Nitric oxide, a biological effector. Electron paramagnetic resonance detection of nitrosyl-iron-protein complexes in whole cells. Eur Biophys J. 1991; 20:1-15. [PubMed: 1657584]

31. Drapier JC, Pellat C, Henry Y. Generation of EPR-detectable nitrosyl-iron complexes in tumor target cells cocultured with activated macrophages. J Biol Chem. 1991; 266:10162-10167. [PubMed: 1645341]

32. Pieper GM, Halligan NL, Hilton G, Konorev EA, Felix CC, Roza AM, Adams MB, Griffith OW. Non-heme iron protein: a potential target of nitric oxide in acute cardiac allograft rejection. Proc Natl Acad Sci U S A. 2003; 100:3125-3130. [PubMed: 12624190]

33. Kim YM, Chung HT, Simmons RL, Billiar TR. Cellular non-heme iron content is a determinant of nitric oxide- mediated apoptosis, necrosis, and caspase inhibition. J Biol Chem. 2000; 275:1095410961. [PubMed: 10753895]

34. Watts RN, Hawkins C, Ponka P, Richardson DR. Nitrogen monoxide (NO)-mediated iron release from cells is linked to NO-induced glutathione efflux via multidrug resistance-associated protein 1. Proc Natl Acad Sci U S A. 2006; 103:7670-7675. [PubMed: 16679408]

35. Toledo JC Jr, Bosworth CA, Hennon SW, Mahtani HA, Bergonia HA, Lancaster JR Jr. Nitric oxide-induced conversion of cellular chelatable iron into macromolecule-bound paramagnetic dinitrosyliron complexes. J Biol Chem. 2008; 283:28926-28933. [PubMed: 18480062]

36. Bosworth CA, Toledo JC Jr, Zmijewski JW, Li Q, Lancaster JR Jr. Dinitrosyliron complexes and the mechanism(s) of cellular protein nitrosothiol formation from nitric oxide. Proc Natl Acad Sci U S A. 2009; 106:4671-4676. [PubMed: 19261856]

37. Krieglstein CF, Cerwinka WH, Laroux FS, Salter JW, Russell JM, Schuermann G, Grisham MB, Ross CR, Granger DN. Regulation of murine intestinal inflammation by reactive metabolites of oxygen and nitrogen: divergent roles of superoxide and nitric oxide. J Exp Med. 2001; 194:12071218. [PubMed: 11696587]

38. Gobert AP, McGee DJ, Akhtar M, Mendz GL, Newton JC, Cheng Y, Mobley HL, Wilson KT. Helicobacter pylori arginase inhibits nitric oxide production by eukaryotic cells: a strategy for bacterial survival. Proc Natl Acad Sci U S A. 2001; 98:13844-13849. [PubMed: 11717441]

39. Butler AR, Megson IL. Non-heme iron nitrosyls in biology. Chem Rev. 2002; 102:1155-1166. [PubMed: 11942790]

40. Richardson DR, Lok HC. The nitric oxide-iron interplay in mammalian cells: Transport and storage of dinitrosyl iron complexes. Biochim Biophys Acta. 2008; 1780:638-651. [PubMed: 18206118]

41. Vanin AF. Dinitrosyl iron complexes with thiolate ligands: physico-chemistry, biochemistry and physiology. Nitric Oxide. 2009; 21:1-13. [PubMed: 19366636]

42. Ueno T, Yoshimura T. The physiological activity and in vivo distribution of dinitrosyl dithiolato iron complex. Jpn J Pharmacol. 2000; 82:95-101. [PubMed: 10877526]

43. Pedersen JZ, De Maria F, Turella P, Federici G, Mattei M, Fabrini R, Dawood KF, Massimi M, Caccuri AM, Ricci G. Glutathione transferases sequester toxic dinitrosyl-iron complexes in cells. A protection mechanism against excess nitric oxide. J Biol Chem. 2007; 282:6364-6371. [PubMed: 17197702]

44. Vanin AF, Malenkova IV, Mordvintsev OI, Miul'sh A. Dinitrosyl complexes of iron with thiolcontaining ligands and their reverse conversion into nitrosothiols. Biokhimiia. 1993; 58:10941103. [PubMed: 8395904]

45. Lu J, Yang J, Tan G, Ding H. Complementary roles of SufA and IscA in the biogenesis of ironsulfur clusters in Escherichia coli. Biochem J. 2008; 409:535-543. [PubMed: 17941825]

46. Tan G, Lu J, Bitoun JP, Huang H, Ding H. IscA/SufA paralogs are required for the [4Fe-4S] cluster assembly in enzymes of multiple physiological pathways in Escherichia coli under aerobic growth conditions. Biochem J. 2009; 420:463-472. [PubMed: 19309314]

47. Varghese S, Tang Y, Imlay JA. Contrasting sensitivities of Escherichia coli aconitases A and B to oxidation and iron depletion. J Bacteriol. 2003; 185:221-230. [PubMed: 12486059] 
48. Flint DH, Emptage MH, Finnegan MG, Fu W, Johnson MK. The role and properties of the ironsulfur cluster in Escherichia coli dihydroxy-acid dehydratase. J Biol Chem. 1993; 268:1473214742. [PubMed: 8325851]

49. Vickery LE, Silberg JJ, Ta DT. Hsc66 and Hsc20, a new heat shock cognate molecular chaperone system from Escherichia coli. Protein Sci. 1997; 6:1047-1056. [PubMed: 9144776]

50. Lu D, Keck JL. Structural basis of Escherichia coli single-stranded DNA-binding protein stimulation of exonuclease I. Proc Natl Acad Sci U S A. 2008; 105:9169-9174. [PubMed: 18591666]

51. Kitagawa M, Ara T, Arifuzzaman M, Ioka-Nakamichi T, Inamoto E, Toyonaga H, Mori H. Complete set of ORF clones of Escherichia coli ASKA library (a complete set of E. coli K-12 ORF archive): unique resources for biological research. DNA Res. 2005; 12:291-299. [PubMed: 16769691]

52. Tamir S, Lewis RS, de Rojas Walker T, Deen WM, Wishnok JS, Tannenbaum SR. The influence of delivery rate on the chemistry and biological effects of nitric oxide. Chem Res Toxicol. 1993; 6:895-899. [PubMed: 8117930]

53. Rogers PA, Ding H. L-cysteine-mediated destabilization of dinitrosyl iron complexes in proteins. J Biol Chem. 2001; 276:30980-30986. [PubMed: 11423535]

54. Zheng L, Cash VL, Flint DH, Dean DR. Assembly of iron-sulfur clusters. Identification of an iscSUA-hscBA-fdx gene cluster from Azotobacter vinelandii. J Biol Chem. 1998; 273:1326413272. [PubMed: 9582371]

55. Takahashi Y, Tokumoto U. A third bacterial system for the assembly of iron-sulfur clusters with homologs in archaea and plastids. J Biol Chem. 2002; 277:28380-28383. [PubMed: 12089140]

56. Gupta V, Sendra M, Naik SG, Chahal HK, Huynh BH, Outten FW, Fontecave M, Ollagnier de Choudens S. Native Escherichia coli SufA, coexpressed with SufBCDSE, purifies as a [2Fe-2S] protein and acts as an Fe-S transporter to Fe-S target enzymes. J Am Chem Soc. 2009; 131:61496153. [PubMed: 19366265]

57. Mettert EL, Outten FW, Wanta B, Kiley PJ. The impact of $\mathrm{O}(2)$ on the Fe-S cluster biogenesis requirements of Escherichia coli FNR. J Mol Biol. 2008; 384:798-811. [PubMed: 18938178]

58. Petrat F, de Groot H, Sustmann R, Rauen U. The chelatable iron pool in living cells: a methodically defined quantity. Biol Chem. 2002; 383:489-502. [PubMed: 12033438]

59. Poole RK, Anjum MF, Membrillo-Hernandez J, Kim SO, Hughes MN, Stewart V. Nitric oxide, nitrite, and Fnr regulation of hmp (flavohemoglobin) gene expression in Escherichia coli K-12. J Bacteriol. 1996; 178:5487-5492. [PubMed: 8808940]

60. Boese M, Mordvintcev PI, Vanin AF, Busse R, Mulsch A. S-nitrosation of serum albumin by dinitrosyl-iron complex. J Biol Chem. 1995; 270:29244-29249. [PubMed: 7493954]

61. Shumaev KB, Gubkin AA, Serezhenkov VA, Lobysheva II, Kosmachevskaya OV, Ruuge EK, Lankin VZ, Topunov AF, Vanin AF. Interaction of reactive oxygen and nitrogen species with albumin- and methemoglobin-bound dinitrosyl-iron complexes. Nitric Oxide. 2008; 18:37-46. [PubMed: 18036856]

62. Cairo G, Recalcati S, Pietrangelo A, Minotti G. The iron regulatory proteins: targets and modulators of free radical reactions and oxidative damage. Free Radic Biol Med. 2002; 32:12371243. [PubMed: 12057761]

63. Rouault T, Klausner R. Regulation of iron metabolism in eukaryotes. Curr Top Cell Regul. 1997; 35:1-19. [PubMed: 9192174]

64. Outten FW, Djaman O, Storz G. A suf operon requirement for Fe-S cluster assembly during iron starvation in Escherichia coli. Mol Microbiol. 2004; 52:861-872. [PubMed: 15101990]

65. Schwartz CJ, Giel JL, Patschkowski T, Luther C, Ruzicka FJ, Beinert H, Kiley PJ. IscR, an Fe-S cluster-containing transcription factor, represses expression of Escherichia coli genes encoding FeS cluster assembly proteins. Proc Natl Acad Sci U S A. 2001; 98:14895-14900. [PubMed: 11742080]

66. Khoroshilova N, Beinert H, Kiley PJ. Association of a polynuclear iron-sulfur center with a mutant FNR protein enhances DNA binding. Proc Natl Acad Sci U S A. 1995; 92:2499-2503. [PubMed: 7708673] 
67. Fleischhacker AS, Kiley PJ. Iron-containing transcription factors and their roles as sensors. Current Opinion in Chemical Biology. 2011 In Press, Corrected Proof.

68. Lu TT, Huang HW, Liaw WF. Anionic mixed thiolate-sulfide-bridged Roussin's red esters [(NO)2Fe(mu-SR)(mu-S)Fe(NO)2]-(R = Et, Me, Ph): a key intermediate for transformation of dinitrosyl iron complexes (DNICs) to [2Fe-2S] clusters. Inorg Chem. 2009; 48:9027-9035. [PubMed: 19705817] 

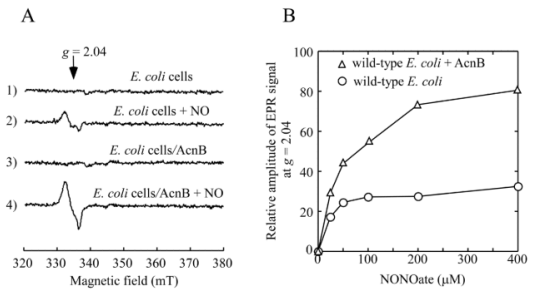

Figure 1. Recombinant aconitase B is modified forming protein-bound DNIC in E. coli cells under NO stress

Exponentially growing $E$. coli cells with or without recombinant aconitase B were concentrated to O.D. at $600 \mathrm{~nm}$ of 6.0 , and treated with a freshly prepared NO-releasing reagent diethylamine NONOate under anaerobic conditions at $37^{\circ} \mathrm{C}$ for $5 \mathrm{~min}$. A) EPR spectra of $E$. coli cells before and after being treated with NONOate. Spectra 1) and 2), $E$. coli cells without recombinant aconitase B before and after being treated with $200 \mu \mathrm{M}$ NONOate at $37^{\circ} \mathrm{C}$ for $5 \mathrm{~min}$. Spectra 3 and 4), E. coli cells with recombinant iron-sulfur protein aconitase $\mathrm{B}(\mathrm{AcnB})$ before and after being treated with $200 \mu \mathrm{M}$ NONOate at $37^{\circ} \mathrm{C}$ for 5 min. B) Titration of NO in E. coli cells. E. coli cells with (open triangles) or without (open circles) recombinant aconitase $\mathrm{B}$ were treated with increasing concentration of NONOate $(0,25,50,100,200,400 \mu \mathrm{M})$ at $37^{\circ} \mathrm{C}$ under anaerobic conditions for $5 \mathrm{~min}$. The amplitude of the EPR signal at $g=2.04$ was plotted as a function of the NONOate concentration used in the $E$. coli cells. The data are representatives from three independent experiments. 


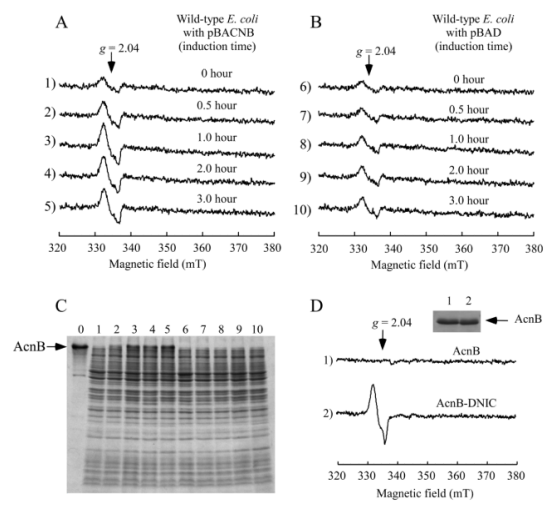

Figure 2. Correlation between the amount of recombinant aconitase B and the NO-mediated formation of protein-bound DNICs in $E$. coli cells

A) EPR spectra of the $E$. coli cells with increasing amount of recombinant aconitase B after NO exposure. E. coli cells containing the expression plasmid pBACNB were induced with $0.03 \%$ arabinose for $0,0.5,1.0,2.0$, and 3.0 hours as indicated. The cells were washed with the M9 minimal medium once, concentrated to O.D. at $600 \mathrm{~nm}$ of 4.0, and treated with 200 $\mu \mathrm{M}$ NONOate at $37^{\circ} \mathrm{C}$ for $5 \mathrm{~min}$. B) EPR spectra of the $E$. coli cells with no recombinant proteins after NO exposure. E. coli cells containing the expression vector pBAD were induced with $0.03 \%$ arabinose for $0,0.5,1.0,2.0$, and 3.0 hours as indicated. The cells were washed with the M9 minimal medium once, concentrated to O.D. at $600 \mathrm{~nm}$ of 4.0, and treated with $200 \mu \mathrm{M}$ NONOate at $37^{\circ} \mathrm{C}$ for $5 \mathrm{~min}$. C) SDS/PAGE gel of the E. coli cells containing either recombinant aconitase $\mathrm{B}$ or an empty vector $\mathrm{pBAD}$. Lane 0 , purified aconitase B (AcnB). Lanes 1-5, E. coli cells containing pBACNB were induced with $0.03 \%$ arabinose for $0,0.5,1.0,2.0$, and 3.0 hours, respectively. Lanes 6-10, E. coli cells containing pBAD were induced with $0.02 \%$ arabinose for $0,0.5,1.0,2.0$, and 3.0 hours, respectively. D) EPR spectra of recombinant aconitase B purified from the E. coli cells exposed to buffer (spectrum 1) or $200 \mu \mathrm{M}$ NONOate (spectrum 2) at $37^{\circ} \mathrm{C}$ for $5 \mathrm{~min}$. The protein concentration of purified recombinant aconitase $\mathrm{B}$ was about $5 \mu \mathrm{M}$. Insert is a photograph of SDS/PAGE gel of purified aconitase B (AcnB) from the E. coli cells treated with buffer (1) or $200 \mu \mathrm{M}$ NONOate (2) $37^{\circ} \mathrm{C}$ for $5 \mathrm{~min}$. 


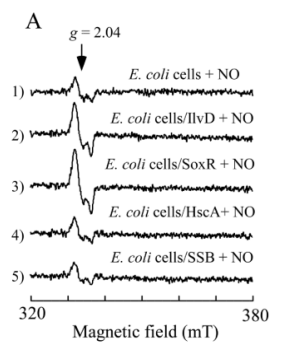

B

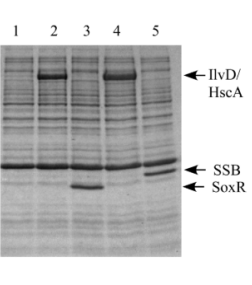

Figure 3. Formation of protein-bound DNICs in other recombinant iron-sulfur proteins in E. coli cells under NO stress

A) EPR spectra of the $E$. coli cells after exposed to NONOate. E. coli cells containing no recombinant protein (spectrum 1), or dihydroxyacid dehydratase [4Fe-4S] cluster (IlvD) (spectrum 2), the redox transcription factor SoxR [2Fe-2S] cluster (SoxR) (spectrum 3), the heat shock cognate protein (HscA) (spectrum 4), or the single stranded DNA binding protein (SSB) (spectrum 5), were concentrated to OD at $600 \mathrm{~nm}$ of 4.0, and exposed to NONOate $(400 \mu \mathrm{M})$ at $37^{\circ} \mathrm{C}$ for $5 \mathrm{~min}$. The EPR spectra were taken under the same experimental conditions. B) The SDS PAGE gel of the E. coli cells with no recombinant protein (lane 1) or with IlvD (lane 2), SoxR (lane 3), HscA (lane 4), or SSB (lane 5). 


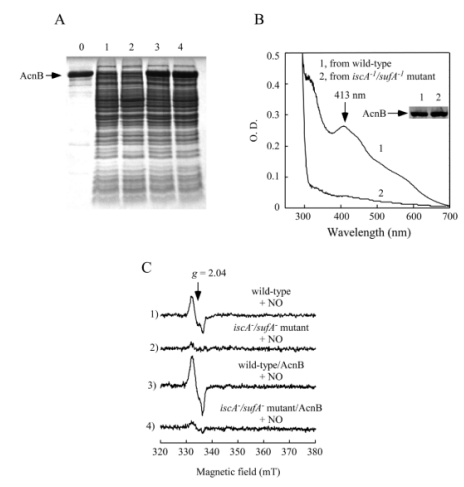

Figure 4. Deficiency of the iron-sulfur cluster assembly largely eliminates the NO-mediated formation of protein-bound DNICs in $E$. coli cells

A) SDS/PAGE gel of the wild-type and the $i s c A^{-1} / s u f A^{-1}$ double mutant $E$. coli cells with or without recombinant aconitase $\mathrm{B}$ grown in the LB medium under aerobic conditions. Lane 0, purified aconitase B (AcnB). Lanes 1 and 2, the wild-type and the $i s c A^{-1} / s u f A^{-1}$ double mutant $E$. coli cells without any recombinant proteins. Lanes 3 and 4, the wild-type and the $i s c A^{-1} / s u f A^{-1}$ double mutant $E$. coli cells containing recombinant aconitase B. B) $\mathrm{UV}$-visible absorption spectra of recombinant aconitase $\mathrm{B}$ purified from the wild-type (spectrum 1) and the $i s c A^{-1} / s u f A^{-1}$ double mutant $E$. coli cells (spectrum 2). The absorption peak at $413 \mathrm{~nm}$ indicates the iron-sulfur cluster in aconitase B. The concentration of purified aconitase B was about $20 \mu \mathrm{M}$. Insert is a photograph of SDS/PAGE gel of purified aconitase $\mathrm{B}$ from the wild-type (1) and the $i s c A^{-1} / s u f A^{-1}$ double mutant (2) cells. C) EPR spectra of the wild-type and the $i s c A^{-1} / s u f A^{-1}$ double mutant $E$. coli cells after being treated with NONOate. $E$. coli cells with or without recombinant aconitase B were concentrated to OD at $600 \mathrm{~nm}$ of 6.0 before NO exposure. Spectra 1) and 2), the wild-type and the $i s c A^{-1} / s u f A^{-1}$ double mutant cells without recombinant aconitase B after the cells were treated with 200 $\mu \mathrm{M}$ NONOate at $37^{\circ} \mathrm{C}$ for $5 \mathrm{~min}$. Spectra 3) and 4), the wild-type and the $i s c A^{-1} / s u f A^{-1}$ double mutant cells with recombinant aconitase B after the cells were treated with $200 \mu \mathrm{M}$ NONOate at $37^{\circ} \mathrm{C}$ for $5 \mathrm{~min}$. The data are representatives from three independent experiments. 
A

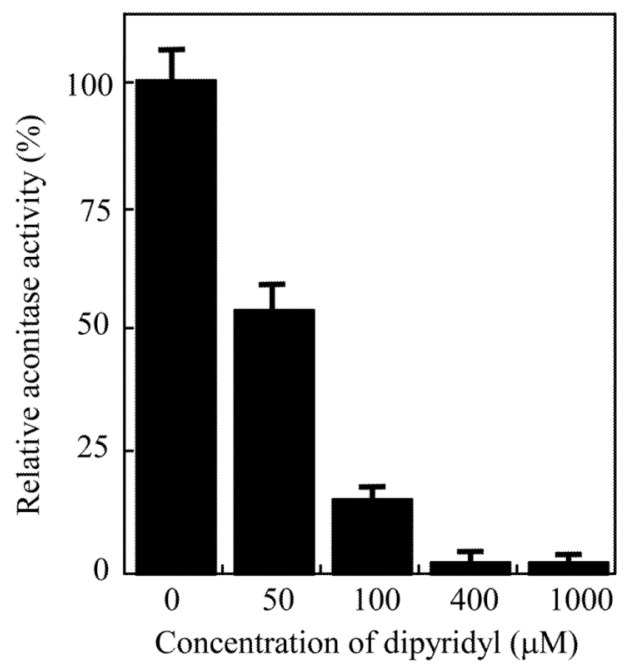

B

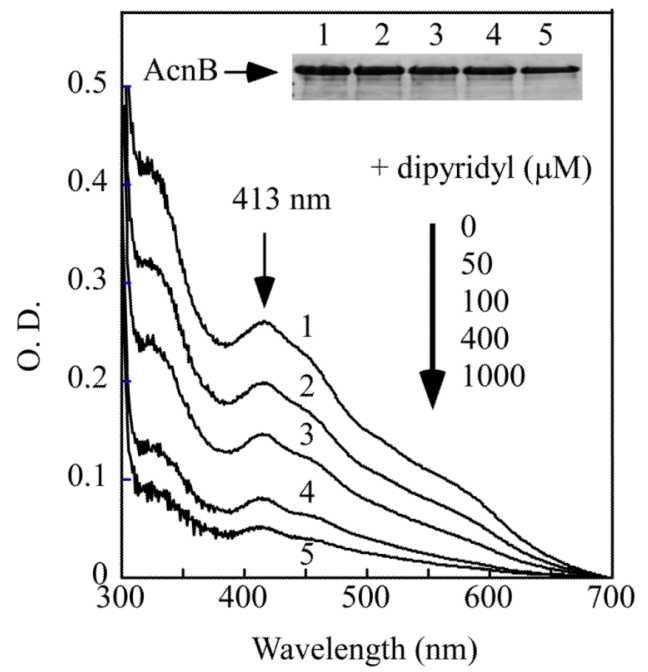

Figure 5. Depletion of "chelatable iron pool" removes iron-sulfur clusters from recombinant aconitase B in $E$. coli cells

A) Inactivation of aconitase B in E. coli cells by an iron chelator 2,2'-dipyridyl. E. coli cells containing recombinant aconitase B were re-suspended in the M9 minimal medium to O.D. at $600 \mathrm{~nm}$ of 4.0. The protein inhibitor chloramphenicol was added to the $E$. coli cell culture

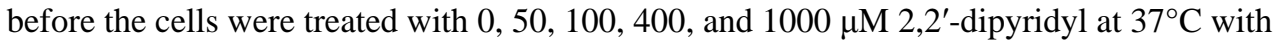
aeration for $40 \mathrm{~min}$. The aconitase activity of the cell extracts prepared from the $E$. coli cells pre-treated with 2,2'-dipyridyl was immediately analyzed. The data were the means \pm SD from three independent experiments. B) UV-visible absorption spectra of recombinant aconitase B purified from the E. coli cells pre-treated with different concentrations of 2,2'dipyridyl for $40 \mathrm{~min}$. The amplitude of the absorption peak at $413 \mathrm{~nm}$ represents the ironsulfur cluster in aconitase B. The protein concentration of purified aconitase B was about 20 $\mu \mathrm{M}$. Insert is a photograph of the SDS/PAGE gel of purified aconitase B from the $E$. coli cells pre-treated with indicated concentrations of 2,2'-dipyridyl for $40 \mathrm{~min}$. 


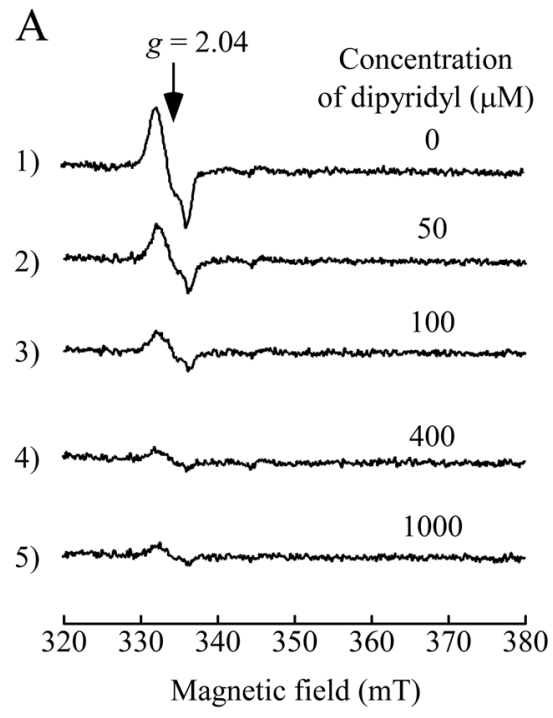

B
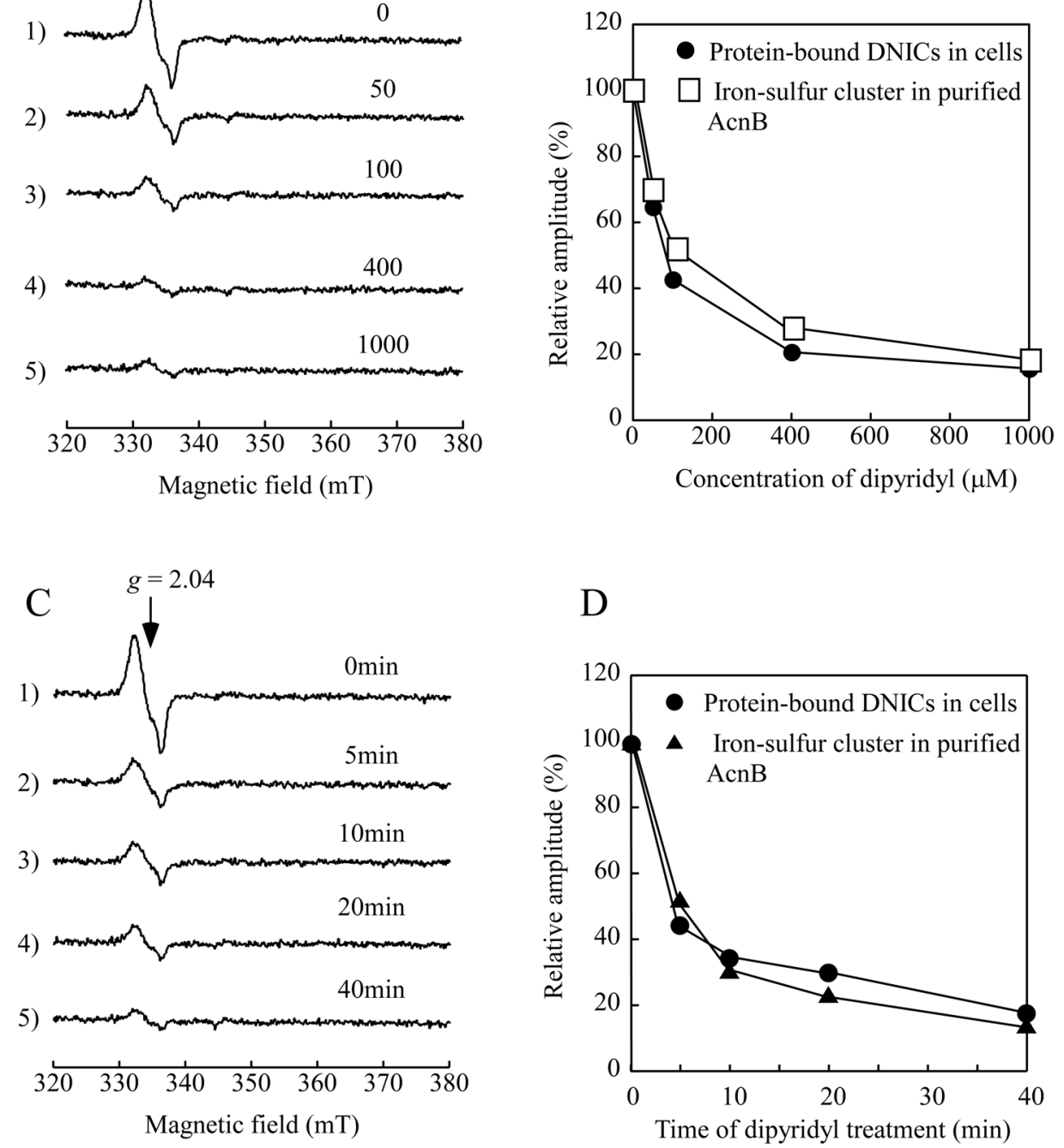

Figure 6. Removal of iron-sulfur clusters in aconitase B prevents the NO-mediated formation of protein-bound DNICs in $E$. coli cells

A) EPR spectra of the NO-exposed E. coli cells pre-treated with different concentrations of 2,2'-dipyridyl. The $E$. coli cells containing recombinant aconitase B were re-suspended in the M9 minimal medium to O.D. at $600 \mathrm{~nm}$ of 4.0, pre-treated with indicated concentration of 2,2'-dipyridyl for $40 \mathrm{~min}$, and exposed to NONOate $(200 \mu \mathrm{M})$ at $37^{\circ} \mathrm{C}$ for $5 \mathrm{~min}$. B) Correlation between the iron-sulfur cluster in recombinant aconitase $\mathrm{B}$ and the proteinbound DNICs formed in the E. coli cells pretreated with different concentrations of 2,2'dipyridyl. After $E$. coli cells were treated with indicated concentration of 2,2'-dipyridyl for $40 \mathrm{~min}$, recombinant aconitase B was purified. The amount of iron-sulfur clusters in aconitase B purified from the $E$. coli cells (open squares) and the amount of protein-bound DNICs (closed circles) in the E. coli cells after NO exposure were plotted as a function of the 2,2'-dipyridyl concentration added in the M9 minimal medium. C) EPR spectra of the NO-exposed $E$. coli cells pre-treated with 2,2'-dipyridyl for different time. The $E$. coli cells containing recombinant aconitase B were re-suspended in the M9 minimal medium to O.D. at $600 \mathrm{~nm}$ of 4.0, pre-treated with $400 \mu \mathrm{M} 2,2^{\prime}$-dipyridyl for indicated time, and exposed to 
NONOate $(200 \mu \mathrm{M})$ at $37^{\circ} \mathrm{C}$ for $5 \mathrm{~min}$. D) Correlation between the iron-sulfur cluster in recombinant aconitase B and the protein-bound DNICs formed in the E. coli cells pretreated with 2,2'-dipyridyl for different time. After E. coli cells were treated with $400 \mu \mathrm{M}$ $2,2^{\prime}$-dipyridyl for indicated time, recombinant aconitase B was purified. The amount of ironsulfur clusters in aconitase B purified from the $E$. coli cells (closed triangles) and the amount of protein-bound DNICs (closed circles) in the E. coli cells after NO exposure were plotted as a function of incubation time with 2,2'-dipyridyl. 


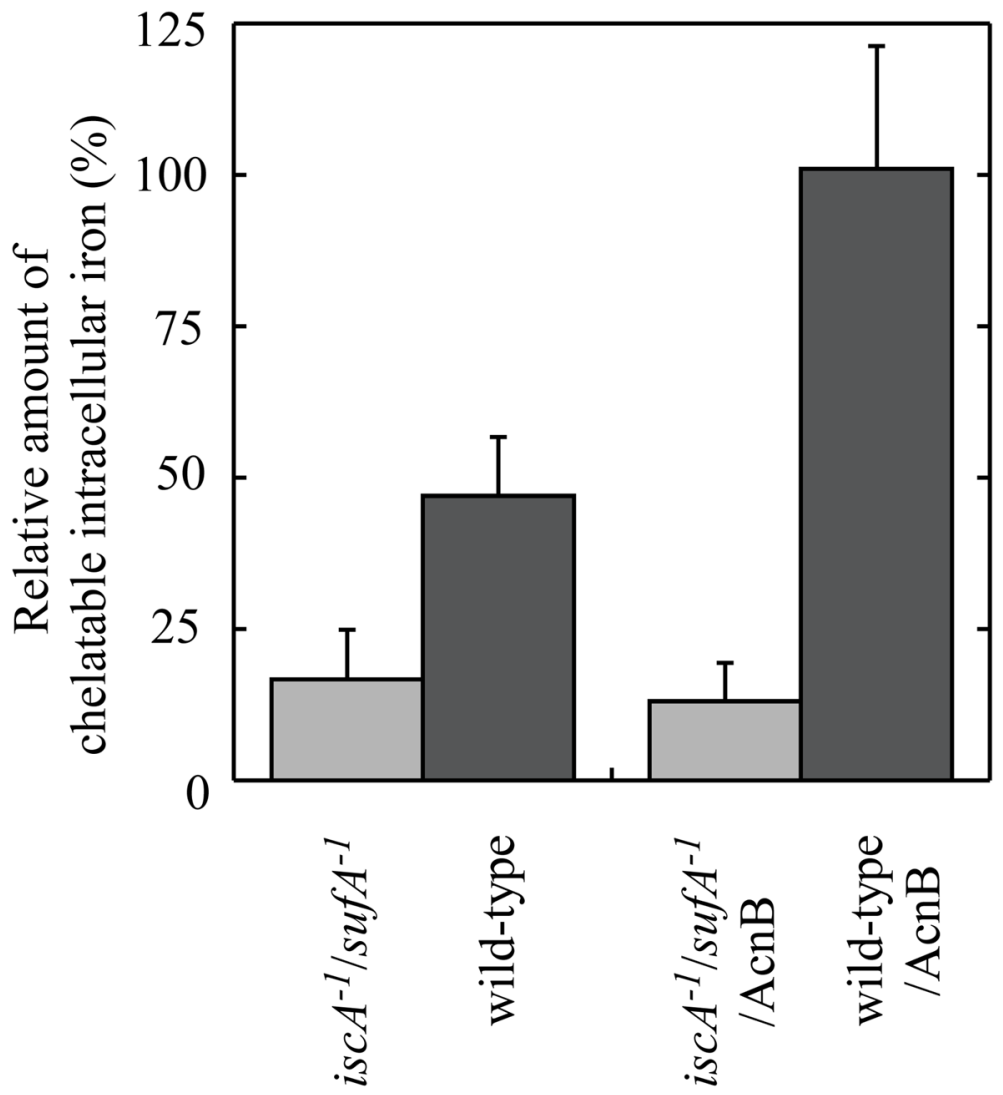

Figure 7. Iron-sulfur clusters in proteins constitute at least part of "chelatable iron pool" in $E$. coli cells

The $i s c A^{-1} / s u f A^{-1}$ double mutant and the wild-type $E$. coli cells without or with recombinant aconitase $B(A c n B)$ were treated with an iron chelator 2,2'-dipyridyl $(400 \mu \mathrm{M})$ at $37^{\circ} \mathrm{C}$ with aeration for $40 \mathrm{~min}$, washed with the $\mathrm{M} 9$ minimal medium once, and resuspended to the O.D. at $600 \mathrm{~nm}$ of 6.0. The "chelatable iron" content in cells was measured after the cells were disrupted by passing through French press and centrifugation as described in the Materials and Methods. Data are the mean \pm SD from three independent experiments. 